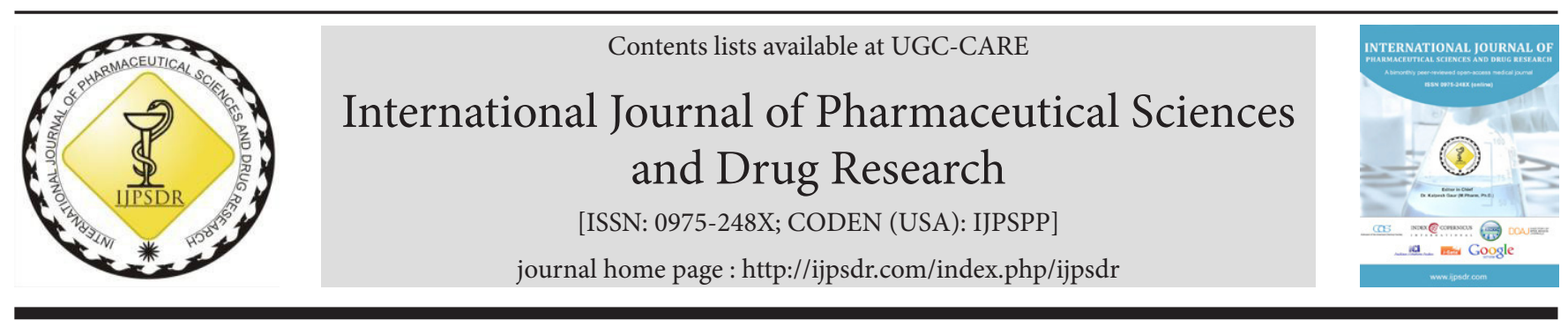

Research Article

\title{
Venlafaxine Hydrochloride Controlled Release Bilayer Tablets: Optimization of Formulation Variable by Using Dyspnea on Exertion
}

\author{
Hitesh P. Dalvadi*, Pritesh J. Patel, Nirmal Vashi, Arindam Paul \\ Department of Pharmaceutics, ROFEL Shri G.M. Bilakhia College of Pharmacy, Rofel Campus, Vapi-Namdha Road, P.B.No. 11, Vapi (W)-396191, Gujarat, India
}

\begin{tabular}{l} 
A R T I C L E I N F O \\
\hline Article history: \\
Received: 08 January, 2020 \\
Revised: 25 February, 2020 \\
Accepted: 03 March, 2020 \\
Published: 30 March, 2020 \\
Keywords: \\
Bilayer tablet, \\
Factorial design, \\
Similarity factor (f2), \\
Theoretical drug release, \\
Venlafaxine HCl. \\
DoI: \\
10.25004/IJPSDR.2020.120208
\end{tabular}

\section{INTRODUCTION}

Formulation of an advanced drug delivery system of existing drugs can improve performance like safety, efficacy and patient adherence. And need for efficient drug therapy with decreased side effects. ${ }^{[1]}$

The multilayered tablets help in the administration of the incompatible drug ${ }^{[2]}$ and provide release in a controlled manner by forming a boundary or swelling layers. Controlled release systems show different controlled drug release pattern such as extended, constant, multimodal, and pulsatile release profiles. ${ }^{[3-5]}$

Bilayered tablets are containing the first layer of a drug as immediate release and the second dose in another layer as extended-release or both as an immediate release.
They are made by compression of two different feed into a single die cavity, another over in first place, in layers. They appear as a sandwich of each layer, seen separately. ${ }^{[6]}$

The main principle of sustained drug delivery (SDD) is to increase the efficacy of a drug and to increase safety and patient adherence. Tablet assists in release of two incompatible active pharmaceutical ingredient (API) in two distinct layers at the same time, one by one release of drugs, and the first release layer as immediate release and subsequent layer as a maintenance dose. ${ }^{[7]}$

The Bilayer Tablet Press is displacement monitoring, single and double-sided. The various Bilayer tablet techniques are L-OROS, Oros® Push-Pull, DUREDAS ${ }^{\text {тм }}$, EN SO TROL, and DUROS Technology. ${ }^{[8]}$

\footnotetext{
*Corresponding Author: Dr. Hitesh P. Dalvadi

Address: ROFEL Shri G.M. Bilakhia College of Pharmacy, Rofel Campus, Vapi-Namdha Road, P.B.No. 11, Vapi(W)-396191, Gujarat, India

Tel.: +91-8980881252

Email $\bowtie$ : hpdalvadi@gmail.com

Relevant conflicts of interest/financial disclosures: The authors declare that the research was conducted in the absence of any commercial or financial relationships that could be construed as a potential conflict of interest.

Copyright (C) 2020 Hitesh P. Dalvadi et al. This is an open access article distributed under the terms of the Creative Commons AttributionNonCommercial-ShareAlike 4.0 International License which allows others to remix, tweak, and build upon the work non-commercially, as long as the author is credited and the new creations are licensed under the identical terms.
} 
The Bi-layer tablet can be employed for various approaches like Polymeric, Floating, Bio-adhesive, and Swelling Delivery System. ${ }^{[9]}$

In present investigation, we developed a bilayer tablet for venlafaxine $\mathrm{HCl}$ with the aim of maintaining drug concentration in body within an effective level. Venlafaxine is an antidepressive agent and belongs to BCS CLASS-I. It acts by inhibiting norepinephrine and serotonin reuptake and weakly inhibit dopamine reuptake. The drug has a half-life of 5 hours. It is administered 75-375 mg/day, given in 2-3 divided doses and taken with food. It is used for management of major depression (MDD), social phobia, generalized anxiety disorder (GAD), panic disorder with or without agoraphobia, neuropathic pain, and vasomotor symptoms in female after menopause and those suffering with breast cancer. ${ }^{[10]}$ An initial screening was designed and evaluated for promising immediate release and then drug release controlling layer of bilayer tablets as to optimize drug release after a release of an immediate layer, with an expectation of bioavailability improvement.

\section{Materials AND Methods}

Venlafaxine was acquired as a gift sample from Aarti Industries. Ltd., Vapi, Gujarat, India, HPMC K100M. Sodium starch glycolate was acquired as a gift sample from Colorcon, Goa. EC was obtained from Astron Chemicals, Ahmedabad, India. The PVP K30 were obtained from Seva Fine Chemicals, Ahmedabad, India, Dicalcium Phosphate and Tale were obtained from West Coast Laboratories (Mumbai, India), Isopropyl Alcohol was obtained from Thomas Baker, Daman, Mannitol and Magnesium Stearate was obtained from Rankem Ltd. (New Delhi), and Loba Chemie Private Ltd. (Mumbai, India). All chemicals and reagents of analytical grade were used.

\section{METHODS}

\section{Dose Calculation Based on Half-life}

Total dose calculation in a bilayer tablet, for loading and maintenance dose of venlafaxine in fast release and retarding layer, was done using the following equation. ${ }^{[11]}$

Pharmacokinetic evaluation of venlafaxine $\mathrm{HCl}$ used for computation of hypothetical drug release profile for 24 hours bilayer tablet was therapeutic concentration $(150 \mathrm{mg} / \mathrm{m})$, bioavailability 55\%, biological half-life ( 5 hours), and volume of distribution $(7.5 \mathrm{~L} / \mathrm{kg})$. The immediate-release part for sustained release venlafaxine $\mathrm{HCl}$ was calculated using the following equation and was observed to be $67.5 \mathrm{mg}{ }^{[12]}$

$\mathrm{D}_{\mathrm{L}}=\left(\mathrm{C}_{\max } \mathrm{V}_{\mathrm{d}}\right) / \mathrm{F}=67.5 \mathrm{mg}$

Where $\mathrm{D}_{\mathrm{L}}=$ Loading dose,

$\mathrm{V}_{\mathrm{d}}=$ Volume of distribution,

$\mathrm{C}_{\text {max }}=$ maximum plasma concentration,

$\mathrm{F}=$ bioavailability fraction.

For 12-hour release profiles, a total dose of $\mathrm{HCl}$ required is calculated by equation
$\mathrm{D}_{\text {total }}=$ Dose $\left[1+0.693 \times\left(\mathrm{t} / \mathrm{t}_{1 / 2}\right)\right]$

Where Total $=$ Total dose

Dose = In fast-release layer $(67.5 \mathrm{mg})$

$\mathrm{t}=$ Time (hrs) for which drug retarding layer is desirable (24 hrs)

$\mathrm{t}_{1 / 2}=$ Biological Half-life of API(5)

$\mathrm{D}_{\text {total }}=67.5[1+0.693 \times(24 / 5)]=292.032 \mathrm{mg}$

Henceforth, the formulation must drug release $67.5 \mathrm{mg}(24.054 \%)$ in a first $\mathrm{hr}$ as conventional tablets and then $34.52 \mathrm{mg}(6.90 \%)$ per hour up to 12 hours after that.

\section{Bilayer Tablet of Venlafaxine $\mathrm{HCl}$ Formulated}

The development of bilayer tablet of venlafaxine $\mathrm{HCl}$ was carried in two different stages. The immediate-release layer (IR) of venlafaxine $\mathrm{HCl}$ and Sustain layer of venlafaxine $\mathrm{HCl}$ was prepared separately. Various preliminary trials were conducted to standardize formula for an individual layer of a bilayer tablet. After the optimization of an individual layer, bilayer tablet was prepared using an optimized formula. Therefore experimental work was divided into three parts.

\section{Immediate-release Layer of Venlafaxine $\mathrm{HCl}$}

Various fast release layers were prepared and compact by direct compression. All ingredients were weighed accurately and gone through \#80 meshes. Required quantities of drug, polymer, and diluents were mixed thoroughly for 5 minutes, except talc and Magnesium stearate. Talc and magnesium stearate were added as glidant and lubricant, mixed well powder blend for 5 minutes. All formulation of tablets was compressed using Oval shape punch of rotary tablet compression machine (Hardik Engg., Ahmedabad).

\section{Sustained-release (SR) Layer of Venlafaxine $\mathrm{HCl}$}

An accurate quantity of drug and other excipients were weighed and mixed uniformly using mortar and pastel. Thirty-two full factorial designs were developed, selecting amounts of HPMC K100M $\left(\mathrm{X}_{1}\right)$ and EC $\left(\mathrm{X}_{2}\right)$ as two independent factors. The dependent variables selected were drug release at 8 hours (Q8), at 12 hours (Q12), and 20 hours (Q20). The selection of levels was based on a preliminary study carried out. All other processing and formulation variable was kept invariable all through an examination. Table 1 delineates a summary of experimental runs, factor combinations, and the actual value of coded levels to experimental study. A solution PVP K30 prepared in IPA (10\%) was added to the tablet powder blend to obtain a damp mass. Extrudes of this mass was obtained by passing it from sieve no \# 22; this extrudes mass were dry in hot air oven at $40^{\circ} \mathrm{C}$ for $30 \mathrm{~min}$. Shifted granules were taken in a polyethylene bag and magnesium stearate and talc were included and mix for $5 \mathrm{~min}$. For the preparation of bilayer tablet, an immediate-release layer was a kept constant and bilayer tablets were formulated 
Table 1: Composition of bilayer tablets

\begin{tabular}{|c|c|c|c|c|c|c|c|c|c|}
\hline \multicolumn{10}{|c|}{ Immediate release layer $(100 \mathrm{mg})^{*}$} \\
\hline Venlafaxine $\mathrm{HCl}$ & & & & 67 & & & & & \\
\hline Sodium starch glycolate & & & & 2 & & & & & \\
\hline PVP K30 & & & & 5 & & & & & \\
\hline Mannitol & & & & 23 & & & & & \\
\hline Magnesium stearate & & & & 2 & & & & & \\
\hline Talc & & & & 1 & & & & & \\
\hline Lake dye & & & & q.s. & & & & & \\
\hline \multicolumn{10}{|c|}{ Sustained release layer $(650 \mathrm{mg})^{*}$} \\
\hline Ingredients & $B L-1$ & $B L-2$ & $B L-3$ & $B L-4$ & $B L-5$ & $B L-6$ & $B L-7$ & $B L-8$ & $B L-9$ \\
\hline Venlafaxine $\mathrm{HCl}$ & 225 & 225 & 225 & 225 & 225 & 225 & 225 & 225 & 225 \\
\hline HPMC K100M & 250 & 300 & 350 & 250 & 300 & 350 & 250 & 300 & 350 \\
\hline EC & 40 & 40 & 40 & 50 & 50 & 50 & 60 & 60 & 60 \\
\hline DCP & 120 & 70 & 20 & 110 & 60 & 10 & 100 & 50 & - \\
\hline Mg stearate & 10 & 10 & 10 & 10 & 10 & 10 & 10 & 10 & 10 \\
\hline Talc & 5 & 5 & 5 & 5 & 5 & 5 & 5 & 5 & 5 \\
\hline PVP K30 in IPA (10\%) & q.s. & q.s. & q.s. & q.s. & q.s. & q.s. & q.s. & q.s. & q.s. \\
\hline Total wt & 750 & 750 & 750 & 750 & 750 & 750 & 750 & 750 & 750 \\
\hline
\end{tabular}

*All quantity in milligrams

by changing in sustained release layer. At the first weighted amount of sustained-release, a layer was added to die cavity and slightly compressed to form a uniform layer, then tablets were compressed finally by adding an immediate layer using composition. ${ }^{[10]}$ The weight of tablet was constant throughout the study. All tablet batches were prepared using an oval punch of a rotary tablet compression machine. Tablets were evaluated for various properties.

\section{Evaluation of Batches of a Bilayer Tablet of Venlafaxine $\mathrm{HCl}$}

\section{Weight Variation}

Twenty tablets randomly selected and find an average weight of 20 tablets by the individual weighting of tablets using electronic weighing balance (Reptech, Mumbai). Not more than two of individual tablet weights deviation from 20 tablets average weight as per limits are given in IP-2007. ${ }^{[13]}$

\section{Hardness}

Hardness of the tablet demonstrates its capacity to withstand mechanical shock while handling. Tablet hardness was estimated utilizing Monsanto hardness tester (Dolphin, Mumbai). It is measure in terms of $\mathrm{kg} / \mathrm{cm}^{2}$. Three tablets were selected randomized from each batch and hardness assessed. Average and standard deviation was computed. ${ }^{[14]}$

\section{Thickness}

Tablet thickness was measured by vernier caliper (Moore and Wright Precision tool, Digimatic Caliper). Tablet thickness ought to be controlled inside a $\pm 5 \%$ variety of standard value. The mean and standard deviation was also calculated. ${ }^{[15]}$

\section{Friability}

Friability of a tablet was determined in the laboratory by Roche friability tester (Scintico Instruments, Mumbai). A pre-weighed 20 tablets were put in a friabilator. Friabilator comprises of a plastic chamber that spins at $25 \mathrm{rpm}$. The tablets were subject to rotation in the friabilator for 100 rotations. At that point tablets were cleaned and reweight; weight reduction is measured. Tablet friability is express in terms of percentage and furthermore, was dictated by following equation: ${ }^{[16]}$

$$
\% \text { Friability }=\frac{\text { Initial weight }- \text { Final weight }}{\text { Initial weight }} \times 100
$$

\section{Disintegration Test (IR layer)}

The test was utilizing apparatus mentioned in Indian Pharmacopeia 2007 using distilled water is used as disintegration media and temperature maintain $37^{\circ} \mathrm{C} \pm$ $2^{\circ} \mathrm{C}$ and time (seconds) taken for finish tablet crumbling with no acceptable mass remaining is estimated. Each batch was taken three samples and the standard deviation was calculated. ${ }^{[13]}$

\section{Drug Content}

Tablet crush and accurately weighted powder equivalent to $100 \mathrm{mg}$ of drug and transferred to a volumetric flask containing $100 \mathrm{~mL}$ phosphate buffer of $\mathrm{pH}$ 6.8. The drug was dissolved by shaking flask and adjusted to volume with buffer. The solution was suitably diluted with phosphate buffer and from resulted solution take $1 \mathrm{~mL}$ and dilute it in $10 \mathrm{~mL}$ volumetric flask with buffer and absorbance of the 
resulted solution was scan at $\lambda \max 225 \mathrm{~nm}$ in UV-Visible spectrophotometer (1800, Shimadzu, Japan). ${ }^{[17]}$

\section{In vitro Drug Release Study}

In vitro release of all formulations was done in the dissolution apparatus (TDT-06, Electrolab, Mumbai) type II as per IP (2007) dissolution method A. One pre-weighed tablet was placed in dissolution medium. The predetermined time interval was $10 \mathrm{~mL}$ aliquots withdrawn, and an equal volume of buffer medium was added. Samples were analyzed by using UV-Visible at $\lambda$ max $225 \mathrm{~nm}$ using $0.1 \mathrm{~N} \mathrm{HCl}$ and $\mathrm{pH} 6.8$ phosphate buffer as a blank. Absorbance was noted down, and concentration was calculated. ${ }^{[13]}$

\section{Accelerated Stability Studies}

Optimized formulation was put in stability samples; the study was carried out on Stability Control Chamber (Remi Instruments Ltd.) at $40^{\circ} \mathrm{C} / 75 \%$ relative humidity for a period of one month. The sample was enveloped by covered aluminum foil, and it was placed in an accelerated stability chamber. Inspecting was at a foreordained time interims of 0,15 , and 30 days. Tablets were assessed for various physicochemical parameters. ${ }^{[18,19]}$

\section{RESULT AND DISCUSSION}

\section{Pre-compression Parameters}

The angle of repose value of BL-1 to BL-9 batches was found between $25.31 \pm 2.01$ and $29.36 \pm 1.14$, respectively. Bulk density was found between $0.41 \pm 0.011$ to $0.441 \pm 0.010$ $\mathrm{gm} / \mathrm{cm}^{3}$ respectively. Tapped density was found between $0.494 \pm 0.023$ to $0.541 \pm 0.011 \mathrm{gm} / \mathrm{cm}^{3}$ respectively. Carr index was found between 15.58 and $23.50 \%$, respectively. Hausner's ratio was found between 1.18 to 1.30, respectively. Data were shown in Table 2.

\section{Physical Parameters}

A hardness of BL- 1 to BL- 9 batches tablets was found to range from $7.33 \pm 0.58$ to $8 \mathrm{~kg} / \mathrm{cm}^{2}$. This indicated a good mechanical strength of tablets. Friability was calculated that also indicates the tablet's strength. Here, friability values for all tablet batches were found within the prescribed limit of $<1 \%$, which passes IP (2007) specification limits. The weight variation BL-1 to BL-9 batches was found between $749.977 \pm 0.951 \mathrm{mg}$ to $750.01 \pm 1.255 \mathrm{mg}$, which complied with the test for weight variation. The Thickness was varying from $4.88 \pm 0.03 \mathrm{~mm}$ to $4.94 \pm 0.0388 \mathrm{~mm}$. \% drug content was seen between $98.83 \pm 0.398 \%$ to $100.7 \pm 0.71 \%$ that also falls in normal range. Drug content uniformity was found good for all batches that were more than $98.83 \%$. From results shown in Table 3, all batches show acceptable physical characteristics. The fourier-transform infrared spectroscopy (FTIR) spectra confirmed drug-excipients compatibility with each other as there were no possible interactions observed.

\section{The In-vitro Drug Release Profile of Formulation}

In vitro drug release study data was shown in Fig. 1; it was found that batch BL-1, BL-4, and BL-7 showed drug release

Table 2: Evaluation parameters for granules of batches BL-1 to BL-9

\begin{tabular}{|c|c|c|c|c|c|}
\hline Batches & Angle of repose* $\left(^{\circ}\right)$ & Bulk density* $(\mathrm{gm} / \mathrm{mL})$ & Tapped density* $(\mathrm{gm} / \mathrm{mL})$ & $\%$ Carr's index & Hausner's ratio \\
\hline BL-1 & $27 \pm 1.21$ & $0.423 \pm 0.017$ & $0.512 \pm 0.019$ & 17.38 & 1.21 \\
\hline BL-2 & $25.36 \pm 2.29$ & $0.437 \pm 0.019$ & $0.541 \pm 0.011$ & 19.22 & 1.24 \\
\hline BL-3 & $29.36 \pm 1.14$ & $0.441 \pm 0.010$ & $0.535 \pm 0.008$ & 17.57 & 1.25 \\
\hline BL-4 & $25.36 \pm 1.29$ & $0.429 \pm 0.021$ & $0.525 \pm 0.017$ & 18.29 & 1.22 \\
\hline BL-5 & $25.12 \pm 1.01$ & $0.413 \pm 0.017$ & $0.497 \pm 0.017$ & 16.90 & 1.20 \\
\hline BL-6 & $28.54 \pm 1.12$ & $0.420 \pm 0.021$ & $0.527 \pm 0.009$ & 20.30 & 1.25 \\
\hline BL-7 & $27.18 \pm 1.32$ & $0.427 \pm 0.01$ & $0.529 \pm 0.013$ & 19.28 & 1.24 \\
\hline BL-8 & $25.31 \pm 2.01$ & $0.417 \pm 0.015$ & $0.494 \pm 0.023$ & 15.58 & 1.18 \\
\hline BL-9 & $27.48 \pm 2.26$ & $0.41 \pm 0.011$ & $0.536 \pm 0.021$ & 23.50 & 1.30 \\
\hline
\end{tabular}

*All Values are expressed as mean $\pm \mathrm{SD}, \mathrm{n}=3$.

Table 3: Physical parameter of bilayer tablets of batches

\begin{tabular}{|c|c|c|c|c|c|}
\hline Batches & Hardness $^{*}\left(\mathrm{~kg} / \mathrm{cm}^{2}\right)$ & Friability (\%) & Weight uniformity* (mg) & Thickness* $(\mathrm{mm})$ & Drug content* $(\%)$ \\
\hline BL-1 & $7.33 \pm 0.58$ & 0.179 & $749.44 \pm 1.147$ & $4.88 \pm 0.068$ & $99.13 \pm 0.211$ \\
\hline BL-2 & $7.33 \pm 0.58$ & 0.290 & $749.777 \pm 1.468$ & $4.843 \pm 0.075$ & $99.43 \pm 0.216$ \\
\hline BL-3 & $8 \pm 0.00$ & 0.231 & $750.477 \pm 1.180$ & $4.90 \pm 0.1$ & $98.83 \pm 0.398$ \\
\hline BL-4 & $7.67 \pm 0.58$ & 0.345 & $749.443 \pm 1.279$ & $4.89 \pm 0.090$ & $100.7 \pm 0.71$ \\
\hline BL-5 & $7.67 \pm 0.58$ & 0.119 & $750.01 \pm 1.255$ & $4.913 \pm 0.065$ & $99.86 \pm 0.734$ \\
\hline BL-6 & $7 \pm 0.00$ & 0.200 & $750.31 \pm 1.09$ & $4.893 \pm 0.015$ & $100.25 \pm 0.705$ \\
\hline BL-7 & $7.67 \pm 0.58$ & 0.166 & $749.977 \pm 0.951$ & $4.893 \pm 0.015$ & $100.25 \pm 0.705$ \\
\hline BL-8 & $7.33 \pm 0.58$ & 0.151 & $749.576 \pm 1.094$ & $.903 \pm 0.021$ & $99.89 \pm 0.842$ \\
\hline BL-9 & $7.33 \pm 0.58$ & 0.162 & $749.243 \pm 1.085$ & $4.94 \pm 0.0388$ & $99.89 \pm 0.802$ \\
\hline
\end{tabular}

*All Values are expressed as mean \pm SD, $\mathrm{n}=3$. 


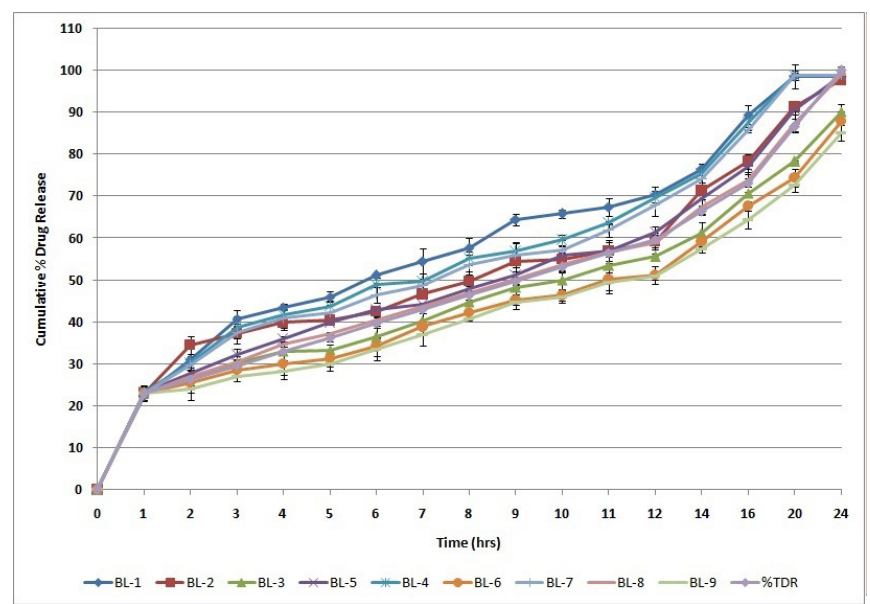

Figure 1: In-vitro drug release study of Bilayer Tablet of BL-1 to BL-9 with \%TDR

Fig. 1: In-vitro drug release study of bilayer tablet of BL-1 to BL-9 with \%TDR

up to 20 hours, and its give $98.71 \pm 0.6,98.91 \pm 1.3$, and $98.95 \pm 0.8 \%$ drug release respectively. The batch BL-2, BL-5, and BL- 8 were able to release drug up to $24 \mathrm{hrs}$ and give $97.78 \pm 1.1,98.78 \pm 1.8$, and $99.11 \pm 0.5 \%$ drug release, respectively. Batch BL-3, BL-6, and BL-9 have resulted in a show that drug release retarding up to 24 hours, but it gives only $90.21 \pm 1.7,87.88 \pm 2.3$, and $85.17 \pm 1.9 \%$ drug releases respectively. So batch BL-8 (300 mg HPMC K100M, $60 \mathrm{mg}$ EC) showed maximum \% drug release than other batches. ${ }^{[10]}$

\section{Optimization of Bilayer Tablet Using $3^{2}$ Factorial Design}

For all nine batches of bilayer tablets prepared independent variable, i.e., amount of HPMC K100M (X1) and amount of
EC (X2), depended variable like \% drug release at 8 hours (Q8), at 20 hours (Q12), and 20 hours (Q20) was evaluate and tabulated in Table 4. ${ }^{[20]}$

A two-independent variable, a three-level full factorial design was constructed RSM performs 9 runs. All observed 9 formulations were fit to a non-linear mathematic model; utilizing design expert 10.0.1 was shown in Table 5. It was seen that the best fit model was quadratic model along with the regression equation created for every response tabulated in Table 5. Model p-value was less than 0.05; model to best fit quadratic model. Multiple regression analysis $\left(\mathrm{R}^{2}\right)$ suggests a proportion of measure of variety around mean as explained by the model. A negative value in the regression equation indicates response value decreases as the amount of factors increases.

Regression analysis ANOVA data for a dependent variable Y1, Y2, and Y3 were for percentage drug release at 8,12 , and 20 hours, as all models of p-values were less than 0.05, all depended variable (Y1, Y2, and Y3) best fitted quadratic model. Comparably, $\mathrm{R}^{2}$ values for responses Y1, Y2, and Y3 are 0.9984, 0.9976, and 0.9969, respectively.

$\%$ drug release at 8 hours

$$
\begin{aligned}
& \mathrm{Q} 8=47.88-6.49 \mathrm{X} 1-1.83 \mathrm{X} 2+0.017 \mathrm{X} 1 \mathrm{X} 2+0.86 \mathrm{X}_{1}^{2} \\
& +0.47 \mathrm{X}_{2}^{2}
\end{aligned}
$$

The amount of drug released at 8 hours from BL-1- BL-9 batches of bilayer tablets varied from 40.74 to $57.74 \%$. A $\mathrm{p}$-value $(\mathrm{p}<0.05)$ concluded that the impact of $\mathrm{X}_{1}$ and $\mathrm{X}_{2}$ was a prominent drug retarding effect at 8 hours. In the regression equation, a negative indication of $\mathrm{X}_{1}$ and $\mathrm{X}_{2}$ indicates that response value decreases as amounts of factors are raised.

\begin{tabular}{|c|c|c|c|c|c|c|}
\hline \multirow[b]{2}{*}{ Sr. No. } & \multirow[b]{2}{*}{ Batch } & \multicolumn{2}{|c|}{ Coded factor level } & \multirow[b]{2}{*}{$\%$ drug release at 8 hrs (Q8) } & \multirow{2}{*}{$\begin{array}{l}\% \text { drug release at } 12 \mathrm{hrs} \\
\text { (Q12) }\end{array}$} & \multirow{2}{*}{$\begin{array}{l}\% \text { drug release at } 20 \mathrm{hrs} \\
(Q 20)\end{array}$} \\
\hline & & $X 1$ & $X 2$ & & & \\
\hline 1 & BL-1 & -1 & -1 & $57.74 \pm 2.3$ & $70.38 \pm 1.9$ & $98.59 \pm 2.8$ \\
\hline 2 & BL-2 & 0 & -1 & $49.80 \pm 2.3$ & $59.3 \pm 1.9$ & $91.49 \pm 1.3$ \\
\hline 3 & BL-3 & +1 & -1 & $44.75 \pm 0.1$ & $55.61 \pm 0.7$ & $78.33 \pm 0.2$ \\
\hline 4 & BL-4 & -1 & 0 & $55.26 \pm 1.6$ & $69.69 \pm 1.6$ & $98.77 \pm 1.1$ \\
\hline 5 & BL-5 & 0 & 0 & $47.9 \pm 0.2$ & $61.44 \pm 1.3$ & $90.70 \pm 2.1$ \\
\hline 6 & BL-6 & +1 & 0 & $42.21 \pm 0.21$ & $51.25 \pm 2.1$ & $74.38 \pm 2.1$ \\
\hline 7 & BL-7 & -1 & +1 & $53.66 \pm 2.3$ & $67.89 \pm 2.7$ & $98.85 \pm 0.6$ \\
\hline 8 & BL-8 & 0 & +1 & $46.89 \pm 1.6$ & $59.03 \pm 1.3$ & $87.29 \pm 2.1$ \\
\hline 9 & BL-9 & +1 & +1 & $40.74 \pm 0.3$ & $50.95 \pm 0.9$ & $72.67 \pm 1.7$ \\
\hline
\end{tabular}

Table 4: Composition of factorial batches with responses

\begin{tabular}{|c|c|c|c|c|c|c|}
\hline \multirow{2}{*}{$\begin{array}{l}\text { Dependent } \\
\text { variables }\end{array}$} & \multicolumn{2}{|c|}{$Q 8=\%$ release at $8 \mathrm{hrs}$} & \multicolumn{2}{|c|}{$Q 12=\%$ release at $12 \mathrm{hrs}$} & \multicolumn{2}{|c|}{$Q 20=\%$ release at $20 \mathrm{hrs}$} \\
\hline & Pvalue & Coefficients & Pvalue & Coefficients & Pvalue & Coefficients \\
\hline Intercept & 0.0002 & 47.88 & 0.0021 & 61.21 & 0.0031 & 90.72 \\
\hline $\mathrm{X}_{1}$ & $<0.0001$ & -6.49 & 0.0003 & -8.36 & 0.0004 & -11.64 \\
\hline $\mathrm{X}_{2}$ & 0.0013 & -1.83 & 0.0169 & -2.07 & 0.0695 & -1.89 \\
\hline $\mathrm{X}_{1} \mathrm{X}_{2}$ & 0.9324 & 0.017 & 0.3771 & -0.54 & 0.1294 & -1.73 \\
\hline $\mathrm{X}_{1}{ }^{2}$ & 0.0488 & 0.86 & 0.4592 & -0.63 & 0.0386 & -4.16 \\
\hline $\mathrm{X}_{2}{ }^{2}$ & 0.1764 & 0.47 & 0.5005 & 0.57 & 0.8144 & 0.30 \\
\hline
\end{tabular}

Table 5: Summary of statistical analysis of measured responses 
$\%$ drug release at 12 hours

$\mathrm{Q} 12=61.21-8.36 \mathrm{X} 1-2.07 \mathrm{X} 2-0.54 \mathrm{X} 1 \mathrm{X} 2-0.63 \mathrm{X}_{1}^{2+}$ $0.57 \mathrm{X}_{2}^{2}$

The amount of drug released at 12 hours from BL-1BL-9 batches of bilayer tablets varied from $50.95 \%$ to $70.38 \%$. A p-value $(\mathrm{p}<0.05)$ concluded that the impact of $\mathrm{X}_{1}$ and $\mathrm{X}_{2}$ was a prominent drug retarding effect at 12 hours. In the regression equation, a negative indication of $X_{1}$ and $X_{2}$ indicates that response value decreases as amounts of factors are raised.

$\%$ drug release at 20 hours

$$
\mathrm{Q} 20=90.72-11.64 \mathrm{X} 1-1.89 \mathrm{X} 2-01.73 \mathrm{X} 1 \mathrm{X} 2-4.16 \mathrm{X}_{1}{ }^{2}
$$$$
+0.30 \mathrm{X}_{2}^{2}
$$

The amount of drug released at 20 hours from BL-1BL- 9 batches of bilayer tablet varied from $72.67 \%$ to $97.59 \%$. A p-value $(\mathrm{p}<0.05)$ concluded that the impact of $\mathrm{X}_{1}$ and $\mathrm{X}_{2}$ was a prominent drug retarding effect at 20 hours. In the regression equation, a negative indication of $X_{1}$ and $X_{2}$ indicates that response value decreases as amounts of factors are raised.

All variables show less than $\mathrm{p}<0.05$, all factors demonstrated a remarkable change in responses.

Contour plots and 3D response plots were constructed using Design Expert 10.0.1; (Figs. 2, 3, and 4) indicates an effect of interaction between factors on dependent variables. Response surface plot was used for further enlightening of dependent and independent variables
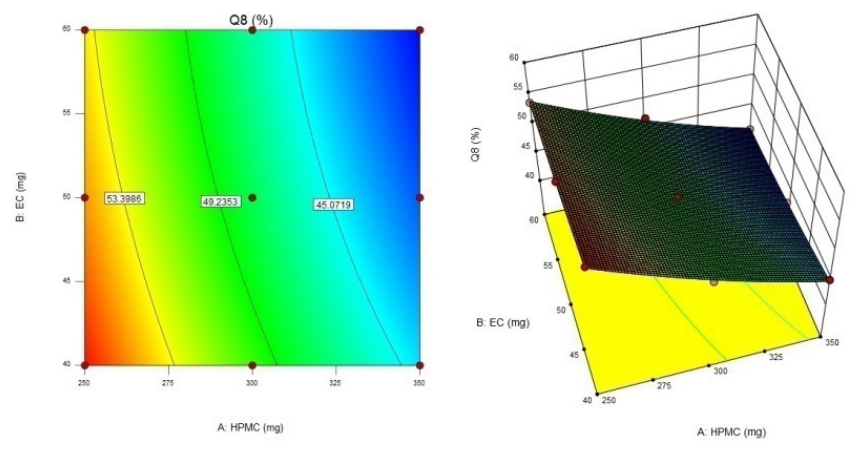

Fig. 2: Response surface and contour plot showing the effects of $X_{1}$ and $\mathrm{X}_{2}$ on the $\%$ drug release at $8 \mathrm{hrs}(\mathrm{Q} 8)$.
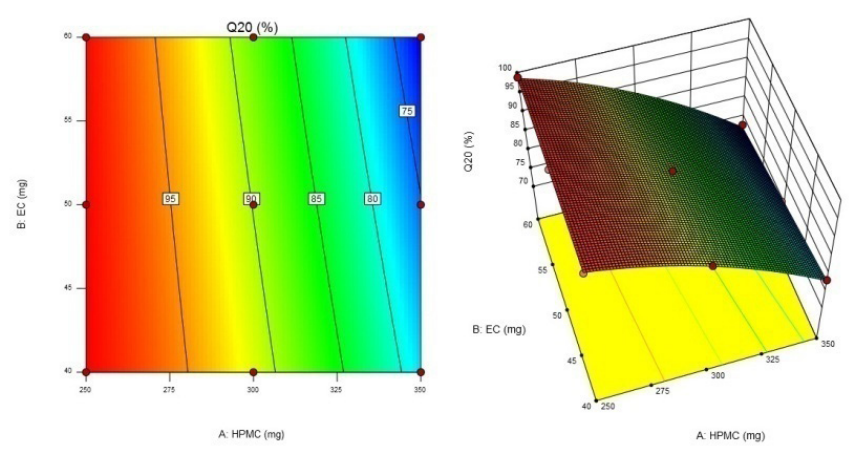

Figure 4: Response surface and contour plot showing the effects of $\mathrm{X}_{1}$ and $\mathrm{X}_{2}$ on the \% dung release at 2 20lus ( (Q20).

Fig. 4: Response surface and contour plot showing the effects of $X_{1}$ and $\mathrm{X}_{2}$ on the $\%$ drug release at $20 \mathrm{hrs}(\mathrm{Q} 20)$. relationship. Fig. 2 depicts an interaction impact among HPMC and EC on \% drug release as a response. With the rise HPMC amount and EC amount, a linear decrease in \% drug release was see. 3D surface plot data was shown in Figs. 3 and 4, characterizing a more drug retarding with an increase in amount of HPMC and EC.

\section{Validation of Optimized Batch}

Design-expert software use for optimization of formulation and contour plots of all respondents use and criteria of the level selected; base on overlay plot final factor concentration for $X_{1}$ and $X_{2}$ were $305.36 \mathrm{mg}$ and $54.03 \mathrm{mg}$. Further, this value base solved equation 2,3 , and 4 , which gives theoretical \% cumulative drug release of $46.39 \%$, 59.79 and $86.58 \%$ at 8 , at 12 , and at 20 hours, respectively. A checkpoint formulation was prepared to utilize the above amount of factors. Estimated values of in vitro drug release at 8 , at 1 , and at 20 hours were found to be $47.12 \pm 2.1,59.89 \pm 2.2$, and $89.06 \pm 2.3$, respectively, which show close agreement to theoretical values.

All post-compression evaluation parameters were performed and results (as shown in Table 6) are found to be within limits. In Fig. 5, there was a correlation of in vitro drug release of check-point batch with percentage
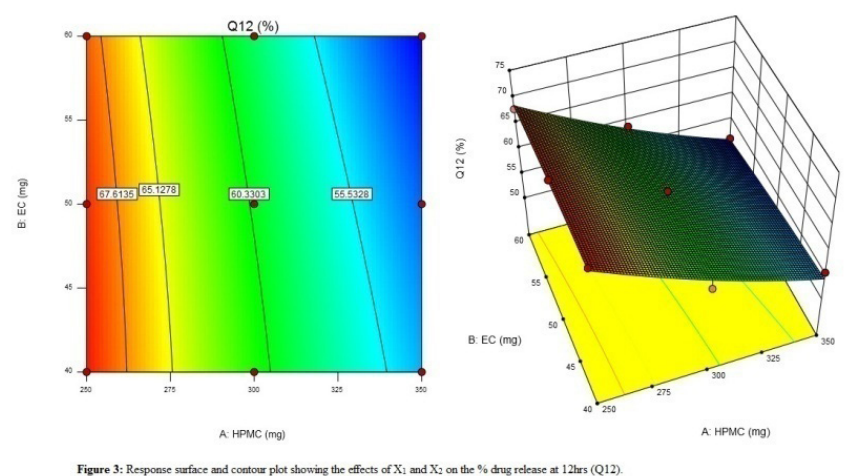

Fig. 3: Response surface and contour plot showing the effects of $X_{1}$ and $\mathrm{X}_{2}$ on the $\%$ drug release at $12 \mathrm{hrs}(\mathrm{Q} 12)$.

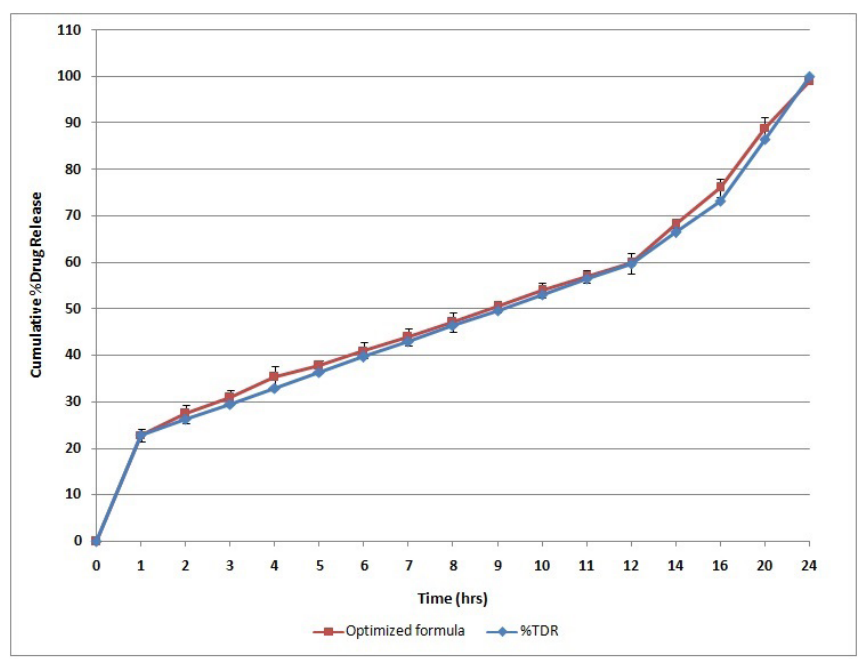

Fig. 5: In-vitro drug release profile of optimized batch and Theoretical \% drug Release profile 
Bilayer Tablet of Venlafaxine Hydrochloride

Table 6: Evaluation of bilayer tablets of optimize batch

\begin{tabular}{ll}
\hline Evaluation parameter & Observation \\
\hline Thickness $(\mathrm{mm})$ & $4.913 \pm 0.065$ \\
Hardness $\left(\mathrm{kg} / \mathrm{cm}^{2}\right)$ & $7.67 \pm 0.58$ \\
Weight variation & $750.05 \pm 0.9002$ \\
Friability (\%) & 0.119 \\
Drug content (\%) & $99.69 \pm 0.786$ \\
\hline
\end{tabular}

theoretical drug release. It revealed that the cumulative percentage drug release of bilayer tablets is similar to the percentage theoretical drug release with similarity factor (f2) is $87 \%$.

\section{Accelerated Stability Studies}

The stability study of optimized batch was performing as per ICH guidelines and revealed that no significant changes in physical parameters (i.e., color, odor, and hardness) when put in stability chamber at temperature and humidity conditions of $40^{\circ} \mathrm{C} / 5 \% \mathrm{RH}$. The result shows that no significant change in drug content was seen over a time of one month.

\section{CONCLUSION}

The bilayer tablet of venlafaxine hydrochloride to increase drug efficacy for efficient treatment of depression was developed. The satisfactory result of treatment can be achieved upon the maintenance of drug concentration within an effective level in the body, so a uniform and constant drug supply are desirable. The fast release layers were prepared and compact by direct compression using super disintegrant (SSG and CCS). Pre and postcompression assessment parameters had seen to be acceptable for the optimized sustained and immediaterelease layer of venlafaxine hydrochloride. An optimized batch of sustained-release (305.36 mg HPMC K100M, $54.03 \mathrm{mg}$ EC) was considered best showing the desired drug release for instant and retarding layer, respectively. Hence the designed bilayered tablet possesses all the formulation qualities, and we achieved \% drug release as per body requirement and comparable to theoretical drug profile, but if it is feasible or not for the production on the large scale must be explored.

\section{REFERENCES}

1. Davis SS. Overcoming barriers to the oral administration of peptide drugs. Trends Pharmacol Sci. 1990;11(9):353-355.

2. Dhiman N, Awasthi A, Jindal S, Khatri S, Dua K. Development of Bilayer Tablets with Modified Release of Selected Incompatible Drugs. Polim. Med. 2016;46(1):5-15.

3. Banker GS, Rhodes CT. Modern Pharmaceutics, $3^{\text {rd }}$ Edn.; Marcel Dekker. 1996;72:575.

4. Zhang Y, Zhang ZR. Preperation of terbutaline sulphate pulsatile release tablet and mechanism elucidation. Acta pharmaceutica Sinica. 2003;38(11):854-858.

5. Qasem JG, Cathcart SH, Irwin JT. Tablets exhibiting reduced drug release variability. US Patents; 7897172B2, Mar. 1, 2011.

6. Deshpande RD, Gowda DV, Mahammed N, Maramwar DN. Bi-layer tablets-An emerging trend: a review. International journal of pharmaceutical sciences and research. 2011 Oct 1;2(10):2534-2544.

7. Shiyani B, Gattani S, Surana S. Formulation and evaluation of bi-layer tablet of metoclopramide hydrochloride and ibuprofen. Aaps Pharmscitech. 2008 Sep 1;9(3):818-827.

8. Gopinath C, Bindu VH, Nischala M. An overview on bilayered tablet technology. Journal of global trends in pharmaceutical sciences. 2013 Apr;4(2):1077-1085.

9. Devtalu SV, Patil AE, Bari MM, Barhate SD. A Review on Novel Approach-Bilayer Tablet Technology. International Journal of Pharmaceutical Sciences Review and Research. 2013 Jul;21(1):46-52.

10. Dalvadi H, Patel P. Formulation and Evaluation of Bilayer Tablet of Venlafaxine Hydrochloride, [Thesis]: Gujarat Technological University. April 2015.

11. Momin M.M., Kane S., Abhang P. Formulation And Evaluation Of Bilayer Tablet for Bimodal Release of Venlafaxine Hydrochloride. Front Pharmacol. 2015;6:144.

12. Reddy KR, Mutalik S, Reddy S. Once-daily sustained-release matrix tablets of nicorandil: formulation and in vitro evaluation. AAPS pharmscitech. 2003 Dec 1;4(4):480-488.

13. Indian Pharmacopeia. 2007 ed. Delhi: The Controller of Publications, Government of India, Ministry of Health and Family Welfare; 2007.

14. Carter S. J., Cooper and Gunn's. Tutorial Pharmacy. New Delhi: CBS Publishers and Distributors; 1986;220-225.

15. Troy D. B., Beringer P. Remington: The science and practice of pharmacy. Lippincott Williams \& Wilkins; 2006.

16. Cooper J, Gunn C. Powder flow and compaction. Tutorial Pharmacy. New Delhi, India: CBS Publishers and Distributors. 1986;6:211-233.

17. Thorat R, Patil P, Aage R, Puranik P, Salve V. Formulation Development And Evaluation of Venlafaxine Hcl Sustained Release Matrix Tablet. International Journal of Pharmacy and Pharmaceutical Sciences. 2013;5(3).

18. Kanvinde SA, Kulkarni MS. Stability of oral solid dosage forms-A global perspective. Pharma times. 2005 May;37(5):9-16.

19. Cartensen J. T. Drug Stability Principles and Practices. $2^{\text {nd }}$ ed. Marcel Dekker Inc.; 1995.

20. Jain N. K. Progress in Controlled and Novel Drug Deliverg System. CBS Publishers and Distributers, New Delhi; 2004. 